cac CÍRCULO

$$
\begin{gathered}
\text { de } \\
\text { lingüística } \\
\text { aplicada a la } \\
\text { comunica } \\
\text { ción }
\end{gathered}
$$

$50 / 2012$

\title{
MALESTAR Y AUTOBIOGRAFÍA
}

\author{
Anna Caballé \\ Universidad de Barcelona \\ annacaballe en ub edu
}

\section{Resumen}

Aplicando aportaciones procedentes del campo de la neurociencia, se puede abordar la narrativa autobiográfica como vinculada a la sensación de bienestar del organismo, de modo que la autobiografía cumpla una función autorreguladora, homoestática, de preservación o restauración de la estabilidad emocional, y por tanto corporal, en el individuo en momentos de crisis o de fractura. En el artículo se muestra cómo conectan con este nuevo marco teórico de concebir la autobiografía tres textos autobiográficos recientes, de Vicente Verdú, Marcos Ordóñez y Javier Pérez Andújar, escritos desde una perspectiva experiencial y con el cuerpo como el escenario principal de las emociones que se describen y analizan.

Palabras clave: autobiografía, neurociencia, Marcos Ordóñez, Javier Pérez Andújar, Vicente Verdú.

Caballé, Anna. 2012.

Malestar y autobiografía.

Círculo de Lingüística Aplicada a la Comunicación 50, 25-38.

http://www.ucm.es/info/circulo/no50/caballe.pdf

DOI http://dx.doi.org/10.5209/rev_CLAC.2012.v50.40620

(C) 2012 Anna Caballé

Círculo de Lingüística Aplicada a la Comunicación (clac)

Universidad Complutense de Madrid. ISSN 1576-4737. http://www.ucm.es/info/circulo 


\begin{abstract}
Uneasiness and autobiography

Taking into account recent developments in the field of neuroscience, autobiographical narrative can be approached as linked to the body's general feeling of well being, so that autobiography may have a self-regulating, homeostatic function, preserving or reinstating emotional stability, and therefore body stability in the individual, in moments of crisis or fracture. This article shows how three recent autobiographical texts connect to this new approach to autobiography, written by Vicente Verdú, Marcos Ordóñez, and Javier Pérez Andújar, from an experiential perspective and with the body as main stage of the emotions they describe and analyze.
\end{abstract}

Key words: autobiography, neuroscience, Marcos Ordóñez, Javier Pérez Andújar, Vicente Verdú.

Índice

I 27

II 30

III 33

Bibliografía 37 
En un artículo publicado en mayo de 2004, titulado "What Are Reading When We Read Autobiography?” (Narrative 12: 121-132), Paul John Eakin admitía sentirse atraído por una idea: la narrativa autobiográfica podría estar vinculada a la sensación de bienestar del organismo ${ }^{1}$. Una idea aparentemente excéntrica a los presupuestos que suelen manejarse en los estudios sobre la autobiografía, si no fuera porque en los últimos años el interés de Eakin, y otros estudiosos, por los avances en el campo de la neurociencia forma parte de una nueva orientación teórica que merece consideración. Podría decirse que si los años ochenta fueron los años del pacto autobiográfico, este concepto, acuñado brillantemente por Philippe Lejeune en 1975 y tan útil ante la necesidad de formalizar la autonomía de la autobiografía en relación a la novela y otros géneros literarios, se vio desplazado en los años noventa por el concepto de la identidad narrativa definido por Paul Ricoeur y aceptado por el propio Lejeune como eje decisivo en torno al cual pivota la naturaleza del acto autobiográfico. Sin embargo, como digo, en la primera década del siglo XXI están surgiendo nuevas orientaciones, cuyas principales aportaciones proceden del campo de la neurociencia. Las investigaciones de neurólogos como Oliver Sacks, Antonio R. Damasio o, entre nosotros, Carlos Castilla del Pino analizando la relación que hay entre memoria, identidad y daños cerebrales han hecho avanzar los estudios sobre la autobiografía, pues permiten comprender con otra precisión conceptos ampliamente manejados por ésta. El más vinculado al campo de la autobiografía es Damasio, director del Institute for the Neurological Study of Emotion and Creativity en la Universidad del Sur de California y quien viene insistiendo en que la identidad narrativa es una noción biológica, antes que lingüística o cultural. El Yo (o Self) no es una entidad formal sino un componente fluido que se actualiza constantemente y que resulta decisivo a la hora de asegurar la continuidad del ser, de la propia identidad, día tras día. Y ¿cómo es posible con los cambios que sufre el individuo a lo largo del tiempo que permanezca la sensación de continuidad, de seguir siendo el que se es y se ha sido? Castilla del Pino en su magnífico estudio Teoría de los

\footnotetext{
${ }^{1}$ Este artículo forma parte del Proyecto FFI2010-16704 del Ministerio de Ciencia e Innovación "Autobiografías de estudiantes: una escritura inmediata" dirigido por la autora.
} 
sentimientos (Tusquets, 2000), donde incluía el esbozo de una teoría del sujeto que desgraciadamente no pudo completar, defendía la idea de que era la memoria autobiográfica quien sostenía la identidad, el Yo, más allá de todas las transformaciones personales. Sin embargo, según Damasio la noción del propio ser no es tanto mental como física y se experimenta antes que nada en el cuerpo siendo éste, en su opinión, el principal responsable de proporcionar al Yo la continuidad que requiere: "Por cada persona que conocemos hay un cuerpo. Puede que nunca nos hayamos detenido a considerarlo, pero ahí está: una persona, un cuerpo; una mente, un cuerpo” ( $L a$ sensación de lo que ocurre. Cuerpo y emoción en la construcción de la conciencia, Debate, 2001: 150). Sí, yo creo que nos hemos detenido más de una vez a considerarlo (la filosofía existencialista, por ejemplo, afirma que todo lo humano cabe en el cuerpo). Blas Matamoro, un maître à penser, en su ensayo más reciente plantea la misma idea: “Cuando digo el cuerpo y me pongo a considerarlo para saber más de él, estoy señalando una referencia: mi cuerpo. Algo mío que remite, a su vez, a otra referencia: el yo. Lo más fácil es confundirlos: yo soy mi cuerpo, mi cuerpo me es, somos lo mismo” (Cuerpo y poder, Fórcola, 2012: 199).

Un cuerpo que, decimos, va cambiando -nadie es el mismo de quince años atrás- y acusa de forma sistemática los ciclos de muerte y nacimiento, que se repiten muchas veces a lo largo de una vida: “algunas de nuestras células sólo sobreviven una semana, la mayoría no más de un año; la excepción son las maravillosas neuronas de nuestro cerebro, las células musculares de nuestro corazón y las células del cristalino” (152). La dialéctica muerte/nacimiento es pues una experiencia continua en el seno de cualquier ser vivo y no única y definitiva como suele aceptarse vulgarmente. Sin embargo, el “edificio biológico”, más allá de sus cambios constantes, de su imparable proceso de envejecimiento, mantiene, según Damasio, una asombrosa estabilidad interna. Nosotros podemos cambiar, y cambiamos externamente, pero, por ejemplo, el proceso en el organismo de combustión integral de los elementos químicos es el mismo, día tras día, año tras año. Con minúsculas desviaciones, porque si el funcionamiento de los órganos, de los tejidos, de las células, se aleja demasiado de los parámetros próximos a la media se produce la enfermedad y la muerte. Así que tenemos un organismo interno que funciona con infinita y pasmosa regularidad y esa sincronía fisiológica es precisamente la que garantiza nuestra supervivencia y nuestro bienestar corporal. En este contexto, el 
cerebro reconstruye la sensación de ser, la unidad del Yo, momento a momento: "No tenemos el ser esculpido en roca y, como la roca, resistente pues a los estragos del tiempo, sino que nuestra sensación de ser es un estado del organismo, resultado de ciertos componentes que funcionan de determinada forma y que se relacionan de determinada manera dentro de cierto parámetros” (152). Un accidente cardiovascular grave y la conciencia, el Yo, desaparecen por completo.

También Castilla del Pino en el libro citado defendía la idea del ser como un estado del organismo y en un Congreso organizado por la UIMP (julio de 2011) en colaboración con la Fundación Carlos Castilla del Pino se trató específicamente de la puesta al día del debate teórico sobre el Self. Damasio, sin embargo, discrepa de quienes sostienen, como Castilla del Pino, que la conciencia es el "gran producto” de la corteza cerebral. Según él es la riqueza de la mente en su amplitud y el perfecto acoplamiento de la corteza cerebral con el tronco encefálico los responsables de proporcionar la conciencia de la existencia, de generar un Yo autobiográfico (Autobiographical Self) que se percibe, de nuevo, de forma inmediata en el cuerpo (en forma de sensación) y que es, como se decía al principio, decisivo. Según Damasio unas formas muy limitadas de ese Yo autobiográfico son compartidas por varias especies: por supuesto los humanos, pero al parecer también los primates, los cetáceos y los perros domésticos poseen una tenue noción de identidad. En todo caso, el Yo que concibe Damasio arraiga en el organismo cumpliendo una función natural: la representación de las secuencias de los acontecimientos en una historia se desarrolla primero en el interior del individuo, sin palabras. Y esa historia se construye sobre la base, siempre dialéctica, en constante proceso de revisión, de recuerdos del pasado, pero también con los recuerdos de los planes que venimos haciendo sobre nosotros mismos. Es la vida pasada y el futuro permanentemente proyectado los dos planos que, conviviendo y madurando conjuntamente en el Yo autobiográfico han sido capaces de generar los diferentes instrumentos de cultura (desde el lenguaje al comercio, la justicia, la creatividad o las artes).

¿Y cómo aplicar las nuevas teorías neurocientíficas al estudio de la autobiografía? Eakin apunta un camino que mencionábamos al comienzo del artículo: la autobiografía puede cumplir una función autorreguladora, homoestática: la preservación o 
restauración de la estabilidad emocional, y por tanto corporal, en el individuo en momentos de crisis o de fractura. Eakin pone como ejemplo los Portraits of Grief (o retratos de la pena): las breves evocaciones de las vidas de las personas que murieron el 11 de septiembre de 2001 en el ataque terrorista a las Torres Gemelas. Se publicaron durante largo tiempo en el New York Times, con una gran inversión de dinero y de esfuerzo (colaboraron ochenta periodistas). Los perfiles trazados quedaban muy lejos del obituario tradicional o del rutinario elogio de la persona fallecida. Se pretendió dotar las evocaciones de una intensa potencia narrativa vinculada a la identidad de cada uno de los fallecidos restableciendo la ilusión de una existencia vivida, ni que fuera fugazmente. Eakin sostiene la idea de que la gente leyó aquellos Retratos con un gran interés y, de algún modo, contribuyeron positivamente a la elaboración del duelo colectivo por el atentado.

Siendo una línea de reflexión interesante, yo aquí prefiero llamar la atención sobre tres textos autobiográficos recientes escritos desde una perspectiva experiencial y que hacen un especial énfasis en el cuerpo como el escenario principal de las emociones que se describen y analizan. Es decir, textos que conectan, entiendo que intuitivamente, con el nuevo marco teórico de concebir la autobiografía. Textos que describen minuciosamente un paisaje interior conflictivo y que contemplan la escritura como un medio de recuperar la homeoestasis perdida. No me estoy refiriendo a que sus autores consideren la literatura como un ejercicio catártico (apenas hay escritores que admitan esta posibilidad) porque en los tres casos (Vicente Verdú, Marcos Ordóñez y Javier Pérez Andújar) se trata de novelistas de amplio espectro literario cuya ambición se mueve por otros derroteros. Me refiero a que siendo escritores que escriben literatura la ponen a trabajar para iluminar un conflicto personal.

Lo señalaba Vicente Verdú en una entrevista hace unos años (Marie Claire, junio de 2008): “Nuestro conflicto está aquí, dentro, no hay que elegir un paisaje”. En efecto, la literatura contemporánea se muestra convencida de que los paisajes interiores, biográficos, resultan incandescentes, tal vez el mayor desafío artístico (aunque eso 
nunca lo suscribiría Hanna Arendt) y aspira a objetivarlos en propuestas narrativas, algunas de ellas intensamente confesionales. La entrevista que Joana Bonet hacía a Vicente Verdú se fundaba en la publicación de un libro impresionante - No Ficción (Anagrama, 2008)- que oscila entre el experimento psicológico y el desahogo confesional y que, en mi opinión, no ha tenido la atención crítica que merece. Sí mereció cierto revuelo un artículo suyo (“Reglas para la superviviencia de la novela”, El País, 17 de noviembre de 2007) en el que reivindicaba la expresión autobiográfica como la forma que más podía ajustarse a los nuevos tiempos de una narrativa tardía y exhausta: "Si la literatura aspira a conocer algo más sobre el mundo y sus enfermos, su elección es la directa, precisa y temeraria escritura del yo”. A Enrique Vila-Matas, pionero en esa modalidad literaria, le pareció que Verdú no descubría con su decálogo ningún nuevo Mediterráneo (Marie Claire, septiembre de 2008). En todo caso, Verdú apoyaría sus ideas con la práctica y puede decirse que No Ficción es, en efecto, un libro “temerario” por el riesgo que corre su autor enfrentándose a sus fantasmas sin la red protectora de la ficción y asumiendo la referencialidad de lo que cuenta. El libro está en la línea de un texto anterior, concebido como un diario de la deshabituación (Días sin fumar, Anagrama, 1989) pero su alcance es superior y podría decirse que en la línea del posterior y excelente Diario de invierno (Anagrama, 2011) de Paul Auster. Su punto de partida es, como lo será en Auster, el traumático paso de la plenitud de la madurez a una incipiente e interiormente confusa decadencia. En No Ficción ese paso tiene que ver con una necesidad de recuperación del bienestar físico del autor, que le resulta imprescindible para seguir escribiendo, y con una impugnación de los mecanismos psicológicos - el perfeccionismo, por ejemplo- que le han conducido a la situación de malestar en la que se halla y de la que arranca el texto: "La salud me devolvería la vida que necesitaba para escribir y la vida que necesitaba para escribir sobre la vida, el sexo, la gravedad y la banalidad. Lesionado, habitado por dolores de estómago, dando a luz a ese bebé mucilaginoso que era la náusea ascendiendo por el cardias me volvía un ser en manos de otro". El texto parte pues de una pérdida pasajera de la homeoestasis, pero también de la radical ignorancia sobre el propio cuerpo, que recuerda un comentario de Ricardo Menéndez Salmón: “El hombre convive con su cuerpo, pero no lo conoce” (La ofensa, Seix Barral, 2007, citado también por el mexicano Pablo Raphael en La Fábrica del Lenguaje, S.A., Anagrama, 2011). El narrador de No Ficción repasa los males físicos 
que sufre, concentrados en el estómago, y los interpreta como un síntoma de algo mucho más profundo: "Lo que ocurre en el estómago es lo que ocurre al yo”. Porque, en efecto, como sostiene, si la salud puede definirse como el silencio de los órganos, "los borborigmos, los pinchazos, los ardores, las diferentes expresiones amargas del estómago, constituyen el idioma de los demonios que cultivamos o se refugian en algunos de nosotros”. El implacable ejercicio introspectivo que implica No Ficción está planteado como un descenso a los infiernos de la naúsea que, sin embargo, mantiene intacta la conciencia y por tanto la capacidad de generar un conocimiento sobre la vida del cuerpo que contiene al Yo y acusa sus malestares, sus conflictos, sus miedos. Es la conciencia del narrador/Verdú la que le lleva a comprender de qué modo las emociones con los años se han ido convirtiendo en lesiones corporales imposibles de extirpar con una intervención quirúrgica, puesto que su esencia se halla disuelta en la psiquis. ¿Y cómo restaurar la salud, el bienestar de la psiquis? La frustración del escritor, sus sentimientos de culpa discurren en paralelo al fracaso de sus experiencias amorosas: con Irena y Paula, por ejemplo, la causa es una abrumadora incompatibilidad de circunstancias. Leamos el comentario del narrador ante el reencuentro con Paula en Veracruz años después de una tímida relación que quedó en mero apunte de lo que podía haber sido: él la ve llegar desde una ventana del hotel en que la está esperando y el resultado, la primera sensación, es decepcionante: “En primer lugar no me encontraba bien bajo la atosigante solanera de la ciudad y entre cuya profusión ambiental presentía los guisos más picantes. En segundo lugar, ella no estaba atractiva. Tenía el pelo hirsuto y un rígido festón en las comisuras de los labios, lo que jamás habría esperado de una chica que guardaba en la memoria como una figura de seda”. Los dos ansían culminar el flechazo sentido años atrás, y lo intentan, sin conseguirlo por diferentes razones que va exhumando el narrador del fondo de su conciencia: “Éramos otros los protagonistas de la habitación y los jóvenes de nueve años atrás parecían descolgados de nosotros, manoteaban casi hundidos y la maniobra de rescate no se desarrollaba nada bien”. Los cuerpos no consiguen el ajuste deseado y la pasión va abriéndose paso como un deseo marchito. Algo parecido ocurrirá con Irena. Por otra parte, Alejandra, su pareja -el amor estable y duradero- enferma y fallece de un cáncer de pulmón dejando al escritor acorralado contra la ficción de la vida que de pronto ha perdido pie, sustento y firmeza. Las experiencias discurren en paralelo a su dependencia de los fármacos: "La química 
es la quilla de la existencia, la línea iridiscente de la que proviene la energía, la verdad, el error y la vida misma”. O bien a sus intentos de curación en manos de psiquiatras y terapeutas. Las correspondencias entre su Yo enfermo y angustiado por querer ser mejor de lo que es, o simplemente ser, libre de sufrimiento, y las heridas que acusa, y causa a su vez, la escritura hacen pensar en la necesidad de una combustión liberadora de la negativa energía acumulada. La agobiante sensación de carecer de méritos suficientes, la necesidad de sofocar las poderosas apiraciones íntimas son experiencias que conducen al protagonista de No Ficción a causarse heridas con las que el cuerpo reacciona a la erosión generada, decíamos, por el desgaste psíquico. El pacto del narrador con la vida es antifaústico, de modo que no hay nada que consiga librarle del coste de la existencia.

III

La estructura de No Ficción es fragmentaria (otro aspecto considerado en su decálogo), articulada a partir de breves unidades o frames narrativos (que podrían compararse con los Portraits of Grief) - una visita al médico, una cita amorosa, la adicción al gelocatil ...- vinculados a una misma identidad, pero no a un argumento. En idéntica línea se halla el tercer y último relato del libro de Marcos Ordóñez, Turismo interior (Lumen, 2010) titulado "Gaseosa en la cabeza”, de escritura tal vez más radical pues integra, como es habitual en la literatura de Marcos Ordóñez, la irritación, la rabia, el desplante verbal. Mientras el libro de Verdú arranca de la preocupación de su autor por una situación vital, física, que ha perdido su anhelado equilibrio, el relato de Ordóñez podría muy bien titularse “Un miedo en observación”, recordando aquel delicioso texto reflexivo de C.S. Lewis A Grief Observed (Una pena en observación, Anagrama, traducción de Carmen Martín Gaite) si no fuera porque han pasado cincuenta años y aquel lenguaje empleado por Lewis se rompió. En todo caso, tampoco es su primer ejercicio autobiográfico: Una vuelta por el Rialto es una obra muy estimable en la que ya se evocaba en clave postmoderna -utilizando un lenguaje de fusión de muchos registros verbales y culturales- la fractura emocional sufrida en su adolescencia (verano del 73; MO nació en 1957), cuando su ambición literaria, su deseo de cumplir con el primer encargo que le hacía un editor importante, se desplomó inesperadamente a causa 
precisamente de la intensidad con que vivió la experiencia. A ella vuelve a referirse en Turismo interior fugazmente: "Escribo desde la mañana hasta la noche, y por la noche me despierto para seguir escribiendo. Mentiría si digo que tengo la menor idea de lo que estoy haciendo. El manuscrito crece y crece, una historia se encadena con otra, hasta que me pierdo en el bosque y se me apaga la linterna. Estoy en el vacío, un vacío desbordado de palabras” (Turismo interior: 236). En Una vuelta por el Rialto Ordóñez analizaba el episodio exhaustivamente: los hechos, sus claves y sus consecuencias en un relato intenso y fracturado, mientras que en Turismo interior el acontecimiento se integra como un miedo más -el miedo a la entropía, al desorden, a la confusión, a la pérdida- porque el libro viene a ser un inventario de los miedos de un hombre. Miedos concretos, precisos, que proceden del interior y del exterior, de uno mismo y de los otros (sobre todo de los otros), del propio ser y de la época en la que se vive. La mente procura mantener una relación dialéctica con ellos pero eso no siempre es posible y a veces los miedos se disparan e inundan al ser de un terror ciego y paralizante. El comienzo del relato, concebido como un monólogo teatral aunque esté dividido en capítulos, nos ubica ya bajo esa luz: “Ahora voy a pedirles que cierren los ojos, rebusquen en su mente y piensen en un miedo, un miedo cualquiera. ¿Lo tienen? Bueno, pues yo también. No es chulería, es que tengo la colección casi completa. Son muchos años de juntar cromos” (211). Lo importante aquí es que los miedos de los que habla Ordóñez se manifiestan en el cuerpo y sus señales son descritas exhaustivamente como estados internos que comunican precisamente la idea de un ser prisionero de su angustia. También el autor de “Gaseosa en la cabeza”, como Verdú, es presa de la ansiedad, de la insatisfacción que genera la creación literaria como marco vital en el que todo depende de la estima que se merece en los otros. Los dos dependen de los fármacos: "Del Vincosedan me pasan al Tranxilium 10. Gran medicamento. Un chute de morfina debe de ser parecido. Caigo en la cama como una marioneta a la que hubieran cortado las cuerdas. Le pregunto a mi psiquiatra si no pueden conectarme a un gota a gota de Tranxilium 10” (281). Verdú localiza el foco de sus tensiones en el estómago, Marcos Ordóñez en el plexo solar. No importa, el caso es que el cuerpo habla y ellos lo escuchan, lo analizan e intentan comprenderlo con la mente analítica de quien procede a describir un objeto que no es él. Podría decirse que así cierran el círculo sobre 
el que se funda la cultura, en términos neurocientíficos: de la existencia a la conciencia, de la conciencia a la creatividad.

Es memorable el capítulo 12 de Turismo interior, con la vívida evocación de un miedo que superó con creces todos los anteriores ubicando la existencia del autor en la fragilidad y el desconcierto. Es la experiencia central de la que parece haber surgido el resto del relato y cuyas consecuencias se prolongan hasta el final (capítulo 20), cuando el autor, como antes Verdú, intuyen haber alcanzado un cierto equilibrio: "Hay que estar constantemente pactando, asumiendo, aprendiendo, reajustando. Todo va tan deprisa, te dices ... todo se mueve y muta y desaparece tan rápido... Ya nos dijeron que la vida era movimiento, pero tanto, y tan veloz ...” (297).

Si Verdú y Ordóñez nos proponen una inquietante y lúcida reflexión sobre el control extremadamente limitado que tenemos sobre nuestro medio interno, ofreciéndonos sendos relatos de su rebelión cuando la presión a la que dicho medio está sometido resulta excesiva, quiero traer aquí un tercer texto ubicado igualmente en "las afueras", no del bienestar del Yo sino de la vida. El paisaje que se le ofrece al lector es igualmente autobiográfico, pero la opción literaria es muy distinta. No es el interior sino el exterior el generador del conflicto, en este caso un difuso malestar que impide la homeostasis con el entorno. Me refiero al delicioso Paseos con mi madre (Tusquets, 2011) de Javier Pérez Andújar. También este texto procede de otro anterior e igualmente autobiográfico (Los príncipes valientes, Tusquets, 2007). En ambos, el segundo es la continuación lógica del primero, el autor/narrador plantea un conflicto que arranca de una falta de acomodación y que impide la homeostasis (aquí social). En Paseos con mi madre se trata de alguien que ha nacido en la periferia de Barcelona, en Sant Adrià de Besòs, una de esas ciudades que crecieron desordenadamente con las sucesivas oleadas de inmigración llegada a Cataluña en los años sesenta. Sant Adrià pertenece al Área Metropolitana de Barcelona pero, al igual que otras localidades del entorno, mantiene una dífícil y quebradiza relación con el centro, la gran ciudad burguesa, Barcelona ciudad: "La Barcelona de las laderas [Montjuich], los promontorios [el Carmel, el Turó de la Peira], los ríos [Besós, Llobregat], los descampados [La Mina], más verdadera porque es más verdad la geografía que la historia”. El comienzo narrativo del libro es majestuoso: un joven estudiante de filología 
(yo misma tuve de alumno a Javier Pérez Andújar en el curso 1991-1992) sale de la Universidad y se dirige al barrio gótico con su carpeta de apuntes cuando, cerca de la Catedral, un policía le sale al paso y le pide la documentación. El narrador le muestra el documento de identidad: “Así que de San Adrián del Besós ¿eh?” “¿Y qué haces entonces en Barcelona?”. “A Barcelona -apostilla el narrador que evoca extensamente la escena que yo aquí sintetizo; escena tal vez inventada pero de una gran fuerza simbólica- no habrá forma de acercarse sin tropezarse con ese entonces. Se extiende una distancia kilométrica entre la primera y la última letra de esta palabra. Entonces, o para salvar ese entonces, voy a mirarle a los ojos al madero que está interrogándome y de golpe nos quedaremos él y yo, percibiéndonos, reconociéndonos el uno en el otro como se reconoce con sólo mirarse la gente que proviene de infiernos diferentes” (26). JPA denuncia la indiferencia que muestra la ciudad hacia el sufrimiento de sus gentes: “Cuando Barcelona visita a sus vecinos es para plantarles una incineradora de basuras” (43). Sin embargo, la aportación del escritor no radica tanto en la exploración del sentimiento de saberse “en las afueras” -de Las afueras de Luis Goytisolo a las afueras de Paseos con mi madre van cincuenta años casi clavados-, como en la aceptación, rozando la épica, del paisaje en el que ha crecido, apropiándoselo como quien se apropia de una bella imagen, a pesar de su fealdad: un paisaje de descampados, bloques de cemento que son ruinas vivientes, minúsculas ventanas enrejadas, alumbrados de bombilla, hogueras gitanas y ríos que arrastran toda la química vomitada por las fábricas que crecen a su alrededor. "Iré siempre buscando paisajes como deflagraciones, con los ojos llenos de llamas, queriendo ser obstinadamente yo mismo en unas calles que quedan fuera de la historia y hasta fuera de mí” (156). También Pérez Andújar le dedica un capítulo (el 11) al miedo; también, como Marcos Ordóñez se convierte en un adicto a la esperanza (el futuro proyectado que antes se mencionaba), cuajada de promesas; también la literatura es una tabla de salvación que permite a los dos autores descubrirse a sí mismos y afianzarse en un dominio que no les excluye porque en realidad les pertenece.

Las tres obras citadas rehúyen el relato pormenorizado y consecuente de una historia personal, para ceñirse a un estructura quebrada que sugiere la conciencia por parte de sus autores de la imposibilidad de narrarse a no ser como fugaces aproximaciones, sucesivas y fragmentarias, fogonazos de una identidad que escribe de sus fracturas antes 
que de sus logros. En todo caso, la noción de autoficción (analizada brillantemente por Manuel Alberca en El pacto ambiguo como una extensión de la novela hacia la autobiografía) se ha quedado corta para explicar la nueva utilización de lo autobiográfico en la creación: podría decirse que se recurre a ella para generar una escritura que se ofrece al lector como la única declinación del mundo al alcance del artista. Y lo cierto es que como hermenéutica ha alcanzado de lleno no solo a la creación, sino al periodismo (los ejemplos son muchos), la filosofía (Michael Onfray en La fuerza de existir parte de su desgarrada infancia para desvelar no sólo la base biográfica de su pensamiento hedonista sino para avalar una convicción: es la propia vida la que proporciona la teoría) o el ensayo (Jorge Riechmann en Bailar sobre una baldosa). Vivimos una época moralmente muy desestabilizadora. Tal vez la única manera en que cabe explorar el complejo orden en que nos hallamos sea a través de lo que Charles Taylor llamó, en Las fuentes del yo, la “resonancia personal”. Sin embargo, son los cuerpos los que ahora se muestran doloridos.

Bibliografía

Alberca, Manuel. 2007. El pacto ambiguo. De la novela autobiográfica a la autoficción. Madrid, Biblioteca Nueva.

Auster, Paul. 2011. Diario de invierno. Barcelona, Anagrama.

Castilla del Pino, Carlos. 2000. Teoría de los sentimientos. Barcelona, Tusquets.

Damasio, Antonio R. 2001. La sensación de lo que ocurre. Cuerpo y emoción en la construcción de la conciencia. Barcelona, Debate.

Eakin, Paul John. 2004. “What Are Reading When We Read Autobiography?” Narrative 12, 121-132.

Goytisolo, Luis. 1958. Las afueras. Barcelona, Seix Barral.

Lejeune, Philippe. 1975. Le pacte autobiographique. París, Seuil.

Lewis, C. S. 1961. Una pena en observación. Traducción de Carmen Martín Gaite. Barcelona 2006, Anagrama.

Matamoro, Blas. 2012. Cuerpo y poder. Madrid, Fórcola. 
Menéndez Salmón, Ricardo. 2007. La ofensa. Barcelona, Seix Barral.

Onfray, Michael. 2008. La fuerza de existir. Barcelona, Anagrama.

Ordóñez, Marcos. 2010. Turismo interior. Madrid, Lumen

Ordóñez, Marcos. 1994. Una vuelta por el Rialto. Barcelona, Anagrama.

Pérez Andújar, Javier. 2007. Los príncipes valientes. Barcelona, Tusquets.

Pérez Andújar, Javier. 2011. Paseos con mi madre. Barcelona, Tusquets.

Raphael, Pablo. 2011. La Fábrica del Lenguaje, S.A. Barcelona, Anagrama.

Riechmann, Jorge. Bailar sobre una baldosa. Zaragoza, Eclipsados.

Taylor, Charles. 1989. Fuentes del yo. La construcción de la identidad moderna. Traducción de Ana Lizón. Barcelona 1996, Paidós.

Verdú, Vicente. 1989. Días sin fumar. Barcelona, Anagrama.

Verdú, Vicente. 2007. “Reglas para la superviviencia de la novela”, El País, 17.11.2007. http://elpais.com/diario/2007/11/17/babelia/1195260623_850215.html.

Verdú, Vicente. 2008a. No Ficción. Barcelona, Anagrama.

Verdú, Vicente. 2008b. “La vida en minúsculas”. Entrevista por Joana Bonet. Marie Claire, junio de 2008. http://www.joanabonet.com/2011/08/vicente-verdu-lavida-en-minusculas/.

Vila-Matas, Enrique. 2008. “La vida como obra de arte”. Entrevista por Joana Bonet. Marie Claire, septiembre de 2008. http://www.joanabonet.com/2011/08/la-vidacomo-obra-de-arte/.

Recibido: 25 junio 2012

Aceptado: 30 julio 2012

Publicado: 31 julio 2012 